\title{
GEOBAORD APPLICATION ON GEOMETRY TEACHING AND SENIOR SECONDARY SCHOOL STUDENTS' ACADEMIC PERFORMANCE IN DEGEMA LOCAL GOVERNMENT AREA, RIVERS STATE
}

\author{
Olajide Deborah \\ Department of Curriculum Studies and \\ Educational Technology \\ Faculty of Education \\ University of Port Harcourt, \\ Rivers State, Nigeria
}

\author{
Prof. C. O. Ekwueme \\ Department of Curriculum Studies and \\ Educational Technology \\ Faculty of Education \\ University of Port Harcourt, \\ Rivers State, Nigeria
}

\author{
Dr. O. F Ndioho \\ Department of Curriculum Studies and \\ Educational Technology \\ Faculty of Education \\ University of Port Harcourt, \\ Rivers State, Nigeria
}

Article DOI: https://doi.org/10.36713/epra2336

\begin{abstract}
This study advocated the efficacy of Geoboard manipulative in senior secondary school students' academic performance in the teaching and learning of Geometry. A sample of one hundred (100) Senior Secondary School One (SSS1) students were used by Simple Random Sampling Technique from two secondary schools in Degema Local Government Area of Rivers State. The instrument for data collection was pretestposttest Geometric Performance Test (GPT). The reliability of the instrument was tested outside the sample with the coefficient of 0.98 using Pearson's Product Moment Correlation (PPMC) method.The instrument was validated by two Mathematics experts. This research was guided by two (2) objectives, two (2) research questions and two (2) hypotheses. The research questions were answered using mean and standard deviation, while analysis of co-variance (ANCOVA) was used to test the hypotheses at 0.05 level of significance. Findings established that Geoboard technique revealed effectiveness of Geoboard in providing adequate structure for in-depth learning of authentic tasks leading to meaningful understanding and hence enhance better performance of Geometry which was perceived as difficult by senior secondary school students. It also demonstrated that Geoboard is a very effective technique in enhancing students' performance in Geometry.
\end{abstract}

KEYWORDS: Geoboard, Manipulative, Teaching-Learning.

\section{INTRODUCTION}

Mathematics as an important subject in the society is seen as an act of playing with numbers and letters. Mathematics is all about logical reasoning and thinking. The relevance of Mathematics cannot be underestimated in our schools and societies today. As a result of this, many scholars have defined Mathematicsin various ways. Mathematics is seen by Gunter and Andreas (2014) as a science that investigate geometric figures, compute numbers, and study abstract topics such as quantity (numbers), structures, space and change. Mathematics is also defined by Elaine (2013), as the science that deals with the logic of shape, quantity and arrangement. Mathematics is all around us, in all we do. Mathematics is the building block for all our daily activities including mobile devices, architecture (ancient and modern) art, money engineering, and even sports. Although, Mathematics has no generally accepted definition, but it can also be described as the study of different topics such as quantity, structure, space and change. Though, through the use of abstraction and logic, Mathematics developed from counting, calculation, measurement and the systematic study of the shapes and motion of 
physical objects (Sanjiv, 2018). Therefore, it is very difficult to imagine a world without mentioning Mathematics.

Mathematics is seen as one of the most important subjects for entry into higher institutions of learning. Similarly, many universities have included some mathematical courses in various courses to be studied in non-Mathematicsprogramme. For instance, students can only be successful in their research work if they have acquired basic knowledge in statistic, a branch of mathematical knowledge.

Mathematics as an important subject to all levels of education has many division, which include:

$\begin{array}{ll}\text { i. } & \text { Foundation } \\ \text { ii. } & \text { Arithmetic } \\ \text { iii. } & \text { Algebra } \\ \text { iv. } & \text { Analysis } \\ \text { v. } & \text { Computational } \\ \text { vi. } & \text { Combinatory } \\ \text { vii. } & \text { Geometry and topology } \\ \text { viii. } & \text { Probability and statistics } \\ \text { ix. } & \text { Computational sciences } \\ \text { x. } & \text { Physical sciences }\end{array}$

All these sub-units came out from two main branches which are pure and applied Mathematics. The pureMathematics includes foundations, arithmetic, algebra, analysis, combinatories, Geometry and topology while the applied Mathematics includes probability and statistics, computational sciences and physical science. One of the divisions of Mathematics is Geometry. Geometry as defined by Adolphus (2011) is an aspect of Mathematicswhich deals with the study of different shapes, these shapes may be plane or solid.Geometry is made an important topic to be learnt in senior secondary schools. The way the topic is being taught in Nigerian schools makes the topic difficult and boring for students to learn.Geometry can be taught in a more meaningful and attractive way by using instructional materials such as Geoboard. A Garboard is defined as a mathematical manipulative which can be used to explore basic concepts in plane Geometry. Despite the relative importance of Geometryin particular and Mathematics in general, it is very discouraging to note that the students' performance in the subject in both internal and external examinations has remained consistently poor (Adolphus, 2011). This is as a result of the report from the West African Examination Council (WAEC) given by Adenipekun (2016) that a total of 858,424 candidates, representing 54.59 percent obtained credit and above in five subjects including English language, but without Mathematics, while 1,213,244 candidates representing 76.84 percent obtained credits and above in a minimum of any five subjects (with or without English language and /or
Mathematics). Learning of Geometry depends on proper teaching-learning method. So proper learning of Mathematics depends on proper teaching. This proper teaching-learning in secondary school in Mathematics especially in Geometry has been a serious issue to investigate (Ali, 2014). Despite how important Mathematics is in our society, its importance and unique position in the school curriculum, it is also disappointing and discouraging to note that students still perform poorly in the subject. This is as a result of the way Mathematics is being taught and most Mathematics teachers have shallow knowledge about how to use manipulative to teach the subject. Mathematics can be taught in a more meaningful and better ways by using manipulative. The use of manipulatives in the teaching of Mathematics has important roles to play; for Mathematics to be properly and well taught, manipulatives are needed. Most Mathematics teachers today make the learning of Mathematics difficult for students because all what they do in the class is the traditional way of teaching where the teacher is seen as an island and the students are seen as the listeners. The teacher is the only active one in the class and the students are passive. The students concur to whatever the teacher says whether it is understood or not. Students in Mathematics class should be active and be able to explore the environment. A Mathematics class should be a constructive class where students relate and interact with one another and the environment; but the reverse is the case these days, Mathematics class is so abstract and learning takes place under a tensed environment. Therefore this study has considered it necessary to investigate the use of Geoboard for teaching-learning of the concept known as Geometry in senior secondary schools in order to improve the teaching and academic performance of students in Geometry.

This research work looked at how some important topics in Mathematics such as Geometry can be well taught and better in the classroom. One of the ways Geometry can be taught better is by using manipulatives such as Geoboard to teach the concept. Geoboards are mathematical manipulatives used to explore basic concepts in plane Geometry such as perimeter properties, area and the characteristics of triangle and other polygons. It consists of a physical board with a certain number of nails driven in around which are wrapped geobands that are made of rubbers. Rubber bands can also be used. Geoboards were invented and popularized in the 1950 s by the English Mathematician, Celeb Gattegno (1911-1988).Fig. 1is the picture of a Geoboard. 


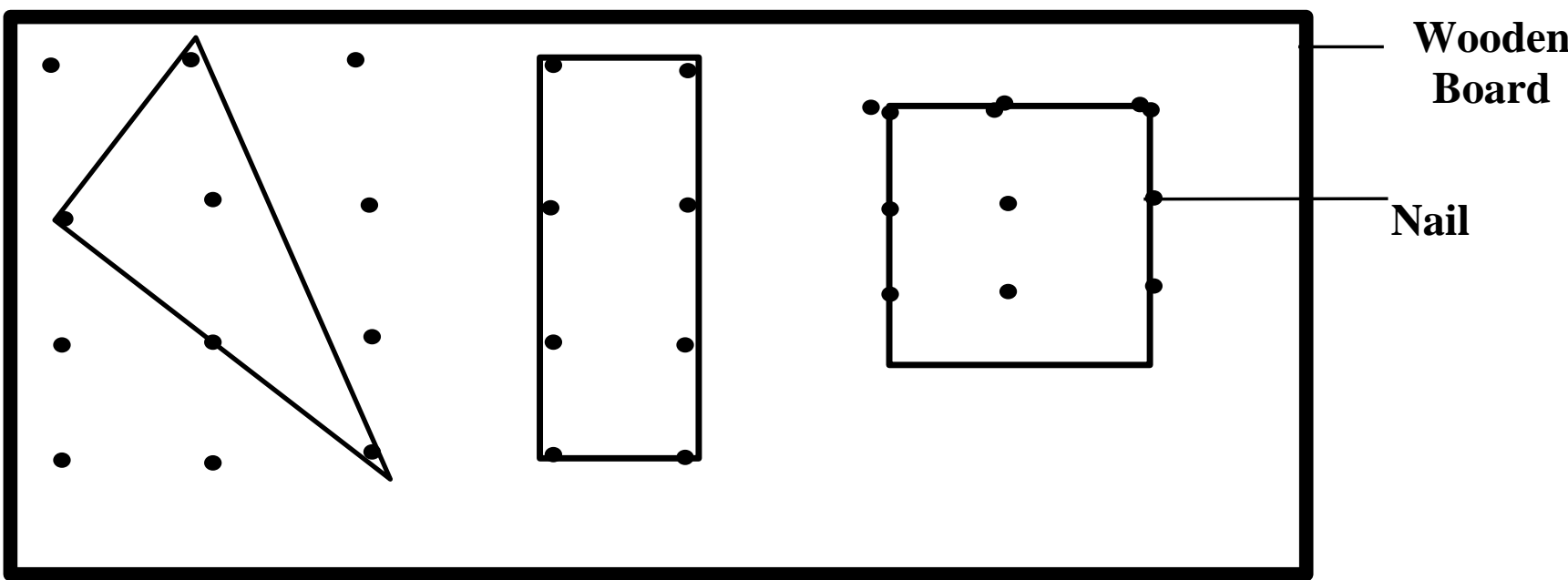

Fig. 1: a wooden $4 \times 8$ Geoboard

The term 'manipulatives' by Lewis (2012) in Ashlee and Peter (2015) is defined as, "items that students use to support hands-on learning. Manipulatives (such as markers, toothpicks, or coins) provide visible models that help students solve problems and develop concepts". Manipulatives are physical objects that are used as teaching tools to engage students in the handson learning of Mathematics. Manipulatives can be used to introduce, practice, or remediate a concept. Manipulatives may be as simple as grains of rice or as sophisticated as a model of our solar system. In Mathematics education, manipulatives are objects which are designed so that learners can perceive some mathematical concepts by manipulating it, hence the name manipulatives. The use of manipulatives provides ways for students to learn concepts through developmental appropriate hands-on experience.

\section{STATEMENT OF THE PROBLEM}

All our daily activities are based on science and technology, although Technology has both positive and negative impact on learners. In all, Mathematics is considered as the mother of all sciences and this makes it important and relevant in our day-to-day activities. Learners see Mathematics as one of the most difficult subjects and so abstract during teaching and learning. This is due to the way the subject is being taught in the classroom.Students lose confidence in themselves thinking that Mathematics is difficult and that it is only meant for some set of people.

\section{AIM AND OBJECTIVES OF THE STUDY}

The aim of this study is to investigate the effectiveness of the use of Geoboard on senior secondary school students' academic performance in Geometry. The objectives of the study are to:
1. Determine the difference between the mean performance of students taught Geometry using Geoboard with those taught using conventional lecture method

2. Compare the gender difference in performance of students taught Geometry using Geoboard.

\section{RESEARCH QUESTIONS}

Two (2) research questions were raised and answered in this study:

1. What is the difference between the mean performance of students taught Geometry using Geoboard with those taught using conventional lecture method?

2. What is the difference between the performance of male and female students taught Geometry using Geoborad?

\section{HYPOTHESES}

The following null hypotheses were tested at 0.05 significant level

$\mathrm{HO}_{1}$ : There is no significant difference between the meanperformance of students taught Geometry using Geoboard with those taught using conventional lecture method.

$\mathbf{H O}_{2}$ : There is no significant difference between the performance of male and female students taught Geometry using Geoboard.

\section{METHODOLOGY}

The design for this study is Quasiexperimental pre-test, post-test nonequivalent group design. Quasi experiment is a form of experimental research extensively used in the social sciences, psychology and education for non-randomized assignment (Nwadinigwe, 2002; shuttle worth, 2008) Quasi experiment research shares similarities with the 
traditional experimental design or randomized controlled trial. It is a design often used in classroom experiments, where experimental and control groups are such naturally assembled groups as intact class. This is used to also enable the effect of the instructional materials in the teaching and learning of Mathematics to be examined in natural settings.

The population of the study consists of all the senior secondary school one (SSS1) students in Degema Local Government Area of Rivers State which is three hundred and seventeen (317) students from ten (10) schools in the local Government Area. Two schools were randomly selected from the government schools in the Local Government Area. One of the schools was used as experimental group while the other was used as control group. The total population sample was one hundred (100) students. Seventy four (74) students were used for experimental group, while twenty six (26) students were used for the control group. A two stage simple random sampling technique was used to assign each of the schools into control and experimental groups. The control group was taught using conventional lecture method or traditional method, while the experimental was taught using Geoboard as manipulatives. The instrument for collection of data for this study was Geometric Mathematics Performance Test (GMPT). The instrument was validated by some experts in the field of Mathematics. The reliability of the instrument was determined by using test-re-test to determine the internal consistency. The reliability coefficient gotten was 0.98 . The research questions were answered using mean and standard deviation while Analysis of Covariance (ANCOVA) was used to test the hypotheses at 0.05 level of significant.

A pretest of GMPT was administered to the two groups (i.e. the experimental and control group) after which, each group was taught by different teachers using the same content for two weeks. The researcher taught the experimental group using Geoboard as manipulatives to each geometric concept, while the control group was taught geometric concept using conventional lecture method. These activities took place for two weeks. A posttest was administered with the question items reshuffled. The students' answer scripts for both pretest and posttest were collected, scored and analyzed statistically.

\section{RESULTS AND DISCUSSION}

Research Question 1: What is the mean difference between the performances of students taught Geometry using Geoboard with those taught using conventional lecture method?

Table 1:Gain scores of students' performance in Mathematics based on the instrumental strategies

\begin{tabular}{|c|c|c|c|c|c|c|c|}
\hline \multirow{3}{*}{ Group } & \multirow{3}{*}{ Strategy } & \multirow{3}{*}{ n } & \multicolumn{2}{|c|}{ Pre-test } & \multirow{3}{*}{\multicolumn{2}{|c|}{$\begin{array}{l}\text { Post-test } \\
\text { SD }\end{array}$}} & \multirow{3}{*}{$\begin{array}{l}\text { Mean gain } \\
\text { scores }\end{array}$} \\
\hline & & & & & & & \\
\hline & & & $\bar{x}$ & SD & & & \\
\hline Experimental & $\begin{array}{l}\text { Geobaord } \\
\text { Instruction }\end{array}$ & 74 & 10.18 & 2.86 & 13.15 & 3.28 & 2.97 \\
\hline Control & $\begin{array}{l}\text { Conventional } \\
\text { method }\end{array}$ & 26 & 11.31 & 2.94 & 13.23 & 2.86 & 1.92 \\
\hline
\end{tabular}

Results on table 1 shows that the mean gain scores of students exposed to Geoboard instrument and conventional method were 2.97 and 1.92 gain respectively. It could therefore be deduced that the students exposed to Geoboard instructional strategy obtained a higher mean gain performance than the students taught with the conventional method. This is shown in figure 2. 


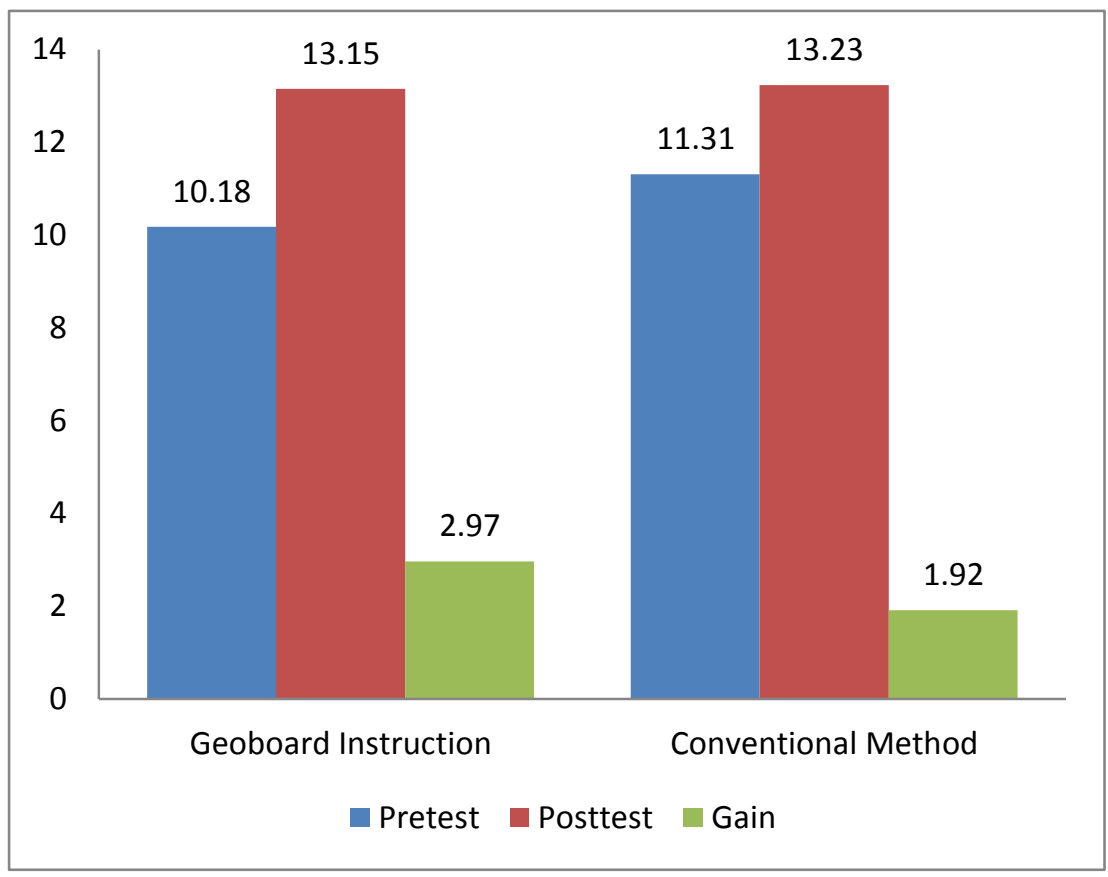

Fig 2:Mean scores of students performances in Mathematics based on the instructional strategies

Research Question 2: What is the difference between the performance of male and female students taught Geometry using Geoboard?

Table 2:Gender performance of students taught geometry using Geoboards

\begin{tabular}{|c|c|c|c|c|c|c|c|c|}
\hline \multirow{2}{*}{ Group } & \multirow{2}{*}{ Strategy } & \multirow{2}{*}{ Gender } & \multirow{2}{*}{$\mathbf{n}$} & \multicolumn{2}{|c|}{ Pre-test } & \multicolumn{2}{|c|}{ Post-test } & \multirow{2}{*}{ Mean gain } \\
\hline & & & & $\overline{\boldsymbol{x}}$ & SD & $\overline{\boldsymbol{x}}$ & SD & \\
\hline \multirow[t]{2}{*}{ Experimental } & $\begin{array}{l}\text { Geoboard } \\
\text { Instruction }\end{array}$ & Male & 49 & 9.92 & 2.98 & 12.98 & 3.44 & 3.06 \\
\hline & & Female & 25 & 10.68 & 2.58 & 13.48 & 3.00 & 2.80 \\
\hline
\end{tabular}

The results on table 2 shows that the male SS1 students exposed to Geoboard instruction had a post-test mean score of $12.98(\mathrm{SD}=3.44)$, pre-test score of 9.92 $(\mathrm{SD}=2.98)$ with a mean gain 3.06. Their female counterparts obtained a post-test mean score of 13.48 $(\mathrm{SD}=3.00)$ and pre-test mean score of $10.68(\mathrm{SD}=2.58)$ indicating a mean gain of 2.80. This showed that the male SS1 students exposed to Geoboard instruction obtained a slightly higher mean gain score than their female counterparts with a mean gain difference of 0.26. Nevertheless, the female students performed better than the male students. This is shown in figure 3 . 


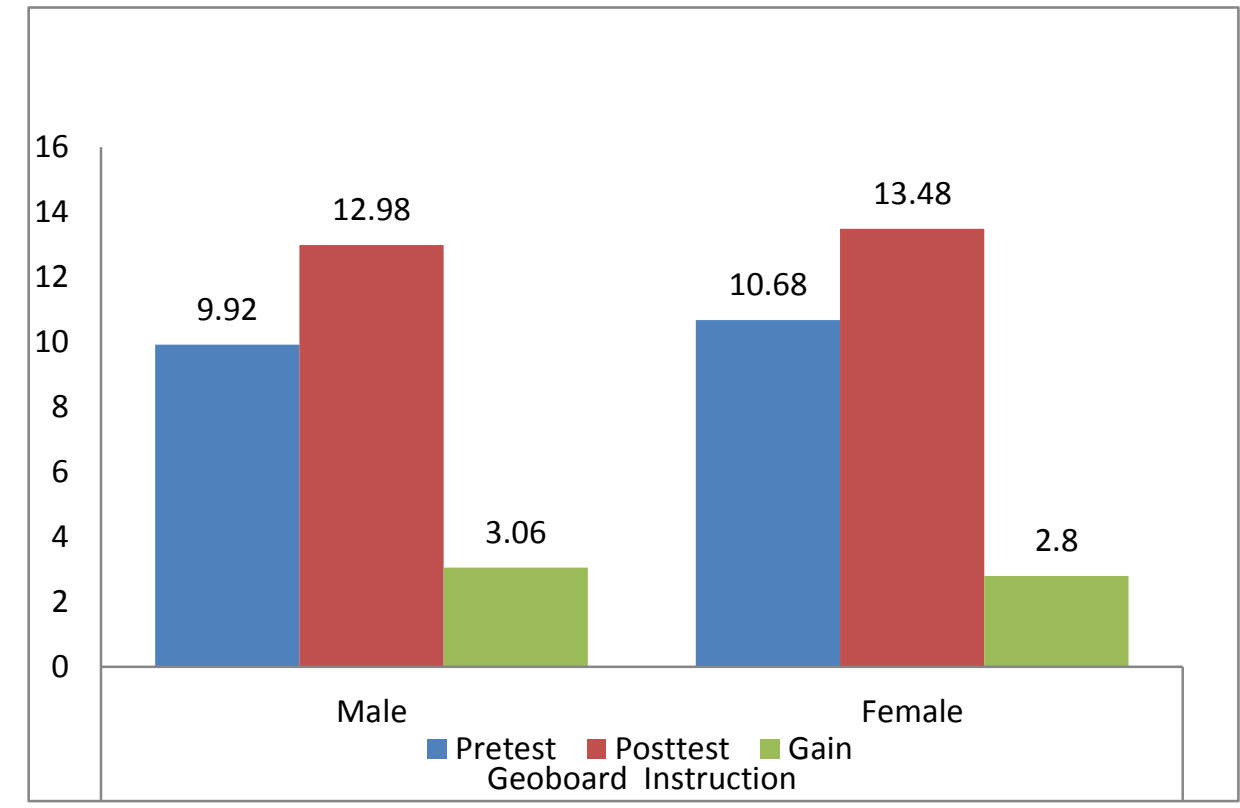

Figure 3:Mean scores of students' performance based on a group and gender.

Hypothesis 1: There is no significant difference between the mean scores of students taught using Geoboard and those taught using conventional method.

Table 3: Summary of ANCOVA on the difference between students mean gain performance in Geometry

Dependent Variable: POSTTEST

\begin{tabular}{lrrrrrr}
\hline Source & $\begin{array}{c}\text { Type III Sum of } \\
\text { Squares }\end{array}$ & $\mathrm{df}$ & Mean Square & $\mathrm{F}$ & $\begin{array}{c}\text { Sig. } \\
\text { Partial Eta } \\
\text { Squared }\end{array}$ \\
\hline Corrected Model & $206.299^{\mathrm{a}}$ & 2 & 103.150 & 12.733 & 0.000 & 0.208 \\
Intercept & 390.181 & 1 & 390.181 & 48.164 & 0.000 & 0.332 \\
PRETEST & 206.170 & 1 & 206.170 & 25.449 & 0.000 & 0.208 \\
GROUPS & 4.451 & 1 & 4.451 & 0.549 & 0.460 & 0.006 \\
Error & 785.811 & 97 & 8.101 & & & \\
Total & 18337.000 & 100 & & & & \\
Corrected Total & 992.110 & 99 & & & & \\
\hline
\end{tabular}

a. R Squared $=.208$ (Adjusted R Squared $=.192$ )

Table 3 shows that F-calculated (0.549) at 0.460 level of significance and it implies that the null hypothesis is accepted since $F$ value $(0.549)>0.05$
Hypothesis 2:There is no significant difference between the performance of male and female students taught Geometry using Geoboard. 
Table 4: Summary of ANCOVA on the difference between male and female students mean score performance in Geometry

Tests of Between-Subjects Effects

Dependent Variable: POSTTEST

\begin{tabular}{lrrrrrr}
\hline Source & $\begin{array}{c}\text { Type III Sum } \\
\text { of Squares }\end{array}$ & df & Mean Square & F & Sig. & $\begin{array}{c}\text { Partial Eta } \\
\text { Squared }\end{array}$ \\
\hline Corrected Model & $148.139 a$ & 2 & 74.069 & 8.227 & 0.001 & 0.188 \\
Intercept & 337.565 & 1 & 337.565 & 37.494 & 0.000 & 0.346 \\
PRETEST & 143.993 & 1 & 143.993 & 15.994 & 0.000 & 0.184 \\
GENDER & 0.247 & 1 & 0.247 & 0.027 & 0.869 & 0.000 \\
Error & 639.226 & 71 & 9.003 & & & \\
Total & 13581.000 & 74 & & & & \\
Corrected Total & 787.365 & 73 & & & & \\
\hline
\end{tabular}

a. $\quad$ R Squared $=.188$ (Adjusted R Squared $=.165$ )

Table 4 revealed that $\mathrm{F}$ calculated $(0.27)$ at $0.869>0.05$ then the null hypothesis is accepted.

\section{CONCLUSION}

The results of the study highlighted the potency of Geoboard technique in fostering deep level, meaningful understanding and promoting students' performance. Geoboard technique was found to be more effective in enhancing students' performance in Geometry. Gender did not significantly influence students' performance of Geometryacross the groups. The use of Geoboard technique as an innovative, purposeful, student centered intervention programme in secondary school students' teaching and learning is one way of ensuring meaningful understanding of Geometry in the post primary schools.

Findings establishedthat Geoboard technique revealed effectiveness of Geobaordin providing adequate structure for in-depth learning of authentic tasks leading to meaningful understanding and hence enhance better performance of Geometry which were perceived as difficult by senior secondary school students.

It also demonstrated that Geoboard is very effective technique in enhancing students' performance in Geometry.

Although, Geoboard was found to be effective in enhancing meaningful performance and promoting higher performance among students in the experimental group, the students in the control group also performed above expectations.

\section{Recommendations}

Based on the findings of the study, the following recommendations are made:

1. Teachers and educators in Mathematics should incorporate Geoboard as a purposeful and effective instructional technique and resource in teaching Geometry so that students could produce better results.

2. The post primary schools board should organize conferences, seminars and workshops for Mathematics teachers and educators to expose them to the design and implementation of
Geoboard as an innovative, purposeful and students centered technique to promote students' academic performance.

\section{REFERENCES}

1. Adenipekun, O. (2016). Improved performance of WAEC: May/June Results. Retrieved online on the $6^{\text {th }}$ of August, 2016 from http://guardian.

2. Adolphus, T. (2011). Problems of Teaching and learning of Geometry in secondary schools in Rivers State, Nigeria. International Journal Emerging science, 1(2), 143-152, June 2011 ISSN: 2222-4254 (c) IJES.

3. Ashlee, C. and Peter, K. (2015). "Mathematical Manipulative: Creating an Environmental for understanding efficiency, engagement and enjoyment", Teach collection of Christian Education. I, ISSN, Article 5.

4. Elaine, J.H. (2013). "What is Mathematics"? Livesscience.com.

5. Gunter, M.Z. and Andreas, L. 2014. Teaching and Learning "What is Mathematics"-Discretization in Geometry and Dynamics. https://www.discretization. de > 2014/09/05.

6. Lewis, B (2012). Manipulative. Retrieved September 12, 2012, from http://k6 educators.about.com/od/educationglossary/g/Manip ulative.htm./od/educationglossary/g/Manipulative.h tm.

7. Sanjiv, D. (2018). What is the full meaning of Mathematics in English? B.S Physics and Mathematics, the Maharaja Sayajirao University of Baroda. 